\title{
Is There a Need for Doppler Vascular Examination for the Diagnosis of Varicose Vein? A Prospective Study
}

\author{
Hussein Safar ${ }^{a}$ Naèl Shawa ${ }^{a}$ Jasem Al-Ali ${ }^{a}$ Mohammad Al-Nassar ${ }^{a}$ \\ Hussein Dashti ${ }^{b}$ Sami Asfar ${ }^{a, b}$ \\ a Vascular Surgery Service, Department of Surgery, Mubarak Al-Kabeer Hospital, and bepartment of Surgery, \\ Faculty of Medicine, Kuwait University Health Sciences Center, Kuwait
}

\section{Key Words \\ Varicose vein - Clinical examination . \\ Doppler ultrasound · Vascular laboratory}

\begin{abstract}
Objective: To compare the validity of a careful clinical examination with venous Doppler studies in the management of patients presenting with varicose veins. Subjects and Methods: Ninety-five consecutive patients presenting with varicose veins from September 1998 to August 1999 were included in this study. Of the 95 patients, 52 were males and 43 females. Eighty-four were expatriate laborers and 11 Kuwaiti nationals. Seventy-one were active workers under the age of 30 . All of the patients underwent a full clinical examination for varicose veins, and a management plan was developed for each patient prior to Doppler venous study. The results of the Doppler studies were then compared with the clinical examination results, and the management plan was changed, if necessary, based on the Doppler results. Results: Both clinical and Doppler examinations were equally effective in diagnosing primary varicose vein and identifying sites of venous incompetence. A family
\end{abstract}

history for varicose veins was found in $21 \%$ and standing for a long period of time was a risk factor in $51 \%$ patients. The most common symptoms were pain and heaviness. Doppler study findings were useful in changing the management plan of 14 (15\%) patients, 6 with recurrent varicose vein and 8 obese patients with chronic venous insufficiency. The majority of the patients $(n=82)$ benefited from surgery and were free of symptoms. Conclusion: This prospective study demonstrated that detailed clinical examination was sufficient to diagnose most patients suffering from primary varicose veins. Doppler vascular studies were useful in changing the treatment modality for those presenting with recurrent varicose vein or obese patients with signs and symptoms of chronic venous insufficiency with no clinically clear varicosity.

Copyright $@ 2004$ S. Karger AG, Basel

\section{Introduction}

Although varicose veins are not generally responsible for serious illness [1], Doppler venous studies are of great help in defining sites of reflux and the follow-up. How-

\begin{tabular}{ll}
\hline KARGER & ( ) 2004 S. Karger AG, Basel \\
Fax +41 61306 1234 34 -7571/04/0131-0043\$21.00/0 \\
$\begin{array}{l}\text { E-Mail karger@karger.ch } \\
\text { www.karger.com }\end{array}$ & $\begin{array}{l}\text { Accessible online at: } \\
\text { www.karger.com } / \mathrm{mpp}\end{array}$
\end{tabular}

Prof. Sami Asfar
Department of Surgery
Faculty of Medicine, Kuwait University
Post Box 24923, 13110 Safat (Kuwait)
Tel. +965 5319475, Fax +965 5319597, E-Mail sami@hsc.kuniv.edu.kw 
ever, instead of carrying out detailed clinical evaluation of the venous system, surgeons tend to become heavily dependent on Doppler studies to diagnose varicose veins. The one vascular laboratory in Kuwait serving a population of two million, performs about 4,000 tests per year. As $41 \%$ of these tests $(1,596 / 3,830)$ are venous studies, a tremendous load is placed on the vascular laboratory. To determine if this degree of Doppler testing is necessary, we decided to compare the validity of clinical examination with venous Doppler studies.

\section{Material and Methods}

Ninety-five consecutive patients presenting with varicose veins from September 1998 to August 1999 were included in this study. Of the 95 patients, 52 were males and 43 females. Eighty-four were expatriate laborers and 11 Kuwaiti nationals. Seventy-one were active workers under the age of 30 . The mean age of the cohort was $34 \pm 5.12$ years. Demographics, symptoms, risk factors, and results of the examinations were entered in a database specifically designed for the study. The same team of surgeons evaluated all the patients, and a standard examination that included cough impulse, percussion, Trendelenburg and tourniquet tests, and Fegan's method (for finding perforators) was done [2]. Clinical diagnosis and type of management plan were determined by staff. The patient was then referred to the vascular laboratory for venous Doppler ultrasound examination of the lower limb. The test was performed using a handheld pocket Doppler ultrasound machine (Meda Sonics, Fremont, Calif., USA). The patient was examined in the supine and standing positions, for superficial long and short saphenous veins, deep femoral, popliteal and tibial veins and perforators.

The results of the Doppler studies were then compared with the clinical examination results, and the management plan was changed based on the Doppler results if necessary. The median follow-up period was 12 months (52\% of cases were followed up at 12 months).

During the follow-up these patients were seen in the Vascular Surgery Outpatient Clinic (Peripheral Arterial and Venous Clinic) by members of the staff who were not aware of the study. Records of patients involved in the study were later reviewed by a senior staff who was aware of the study, for evaluating patient satisfaction.

\section{Statistical Analysis}

Data were analyzed with GraphPad Instat 3.01, GraphPad Software, San Diego, Calif., USA. Fisher's exact test was used for nominal variables, and two-tailed $t$ test for continuous variables. A $p$ value of 0.05 or less was considered significant.

\section{Results}

The patient's demographics, symptoms and risk factors are shown in table 1. Pain and heaviness was the most frequent presenting symptoms (64\%), and long periods of standing were the most common occupational risk factor
Table 1. Demographic data, symptoms and risk factors

\begin{tabular}{lrr}
\hline & \multicolumn{2}{l}{ Patients } \\
\cline { 2 - 3 } & $\mathrm{n}$ & $\%$ \\
\hline Demographics & 53 & 55 \\
$\quad$ Male sex & 71 & 75 \\
Age less than 30 (year) & 11 & 11 \\
Kuwaiti & 20 & 21 \\
Family history & 6 & 6 \\
Recurrent varicose vein & & \\
Symptoms & 61 & 64 \\
Pain/heaviness & 21 & 22 \\
Pain/heaviness/swelling & 8 & 8 \\
Cosmetic & 5 & 5 \\
Chronic venous insufficiency ${ }^{1}$ & & \\
Risk factors & 49 & 51 \\
Long standing & 19 & 20 \\
Pregnancy/long standing & 20 & 20 \\
No risk factor & 4 & 4 \\
Pregnancy & 1 & 1 \\
Deep vein thrombosis & & \\
\hline
\end{tabular}

1 Chronic venous insufficiency is defined as: patients presenting with vague aches in the lower limbs on long standing with edema and/or skin changes (spiders, fine reticular veins, skin dryness or pigmentation in the lower third of the leg).

(51\%). Of the 95 patients, $20(21 \%)$ had a family history of varicose vein.

A comparison of clinical and Doppler findings is given in table 2, indicating no statistically significant difference between them. In $81(85 \%)$ of the patients, the results of the Doppler venous studies did not change the surgical management plan; $82(86.3 \%)$ were treated surgically, 10 $(10.5 \%)$ were treated with sclerotherapy, and 3 were treated conservatively (compression stocking) (table 3). Of the 10 treated with sclerotherapy, 2 had a recurrence. However, in $14(15 \%)$ patients the plan had to be changed. Six of these had recurrent varicose veins, while 8 were obese with chronic venous insufficiency, presenting with spiders and reticular varicosity without clinically obvious varicose veins. In these cases, management changes involved surgery for perforators and/or sclerotherapy in addition to high ligation of the saphenofemoral and/or saphenopopliteal junctions. During the follow-up period most patients were satisfied by the results of surgery. 
Table 2. Clinical and laboratory examinations

\begin{tabular}{|c|c|c|c|c|c|}
\hline \multirow[t]{2}{*}{ Site of incompetence } & \multicolumn{2}{|c|}{ Clinical } & \multicolumn{2}{|c|}{ Vascular lab } & \multirow[t]{2}{*}{$\mathrm{p}$ value } \\
\hline & $\mathrm{n}$ & $\%$ & $\mathrm{n}$ & $\%$ & \\
\hline 1 Saphenofemoral junction (SFJI) & 3 & 3 & 6 & 6 & NS \\
\hline 2 Long saphenous vein (LSVI) & 14 & 15 & 12 & 13 & NS \\
\hline 3 Short saphenous vein (SSVI) & 3 & 3 & 5 & 5 & NS \\
\hline 4 Perforators (PI) & 5 & 5 & 5 & 5 & NS \\
\hline 5 SFJI, LSVI, SSVI and PI & 5 & 5 & 6 & 6 & NS \\
\hline 6 SFJI and LSVI & 36 & 36 & 32 & 33 & NS \\
\hline 7 SFJI, LSVI, and SSVI & 16 & 17 & 18 & 19 & NS \\
\hline 8 SSVI and PI & 6 & 6 & 7 & 7 & NS \\
\hline 9 LSVI and PI & 7 & 7 & 4 & 4 & NS \\
\hline
\end{tabular}

$\mathrm{NS}=$ Not statistically significant $(\mathrm{p}>0.05)$.
Table 3. Surgical management

\begin{tabular}{lcc}
\hline & $\mathrm{n}$ & $\%$ \\
\hline Operation & 82 & 86 \\
Sclerotherapy & 10 & 10 \\
Conservative & 3 & 3 \\
Recurrence & 2 & $2^{\mathrm{a}}$ \\
\hline
\end{tabular}

a Sclerotherapy group.

\section{Discussion}

In this cohort study, more males than females presented with varicose vein diseases, inconsistent with a previous report [3]. The probable explanation is that most females in this society wear long dresses for religious and cultural reasons, therefore unsightly reticular or spider varicosities are of no great concern to most of them. On the other hand young laborers (mostly expatriates) who spend long hours standing in different jobs (maids, house helpers, builders, security officers etc.) develop symptomatic varicosities and seek medical advice. As these laborers comprised $75 \%$ of our sample, the true prevalence of varicose vein in Kuwait may not have been reflected in this study.

The symptoms and risk factors in our cohorts were similar to those reported in the literature [1]. Both detailed clinical examination and Doppler examination of the venous system of the lower limb were equally effective in identifying sites of venous incompetence (table 2). The most common site of incompetence was the saphenofe- moral junction and the least common site was the short saphenous vein. Doppler ultrasound examination did not provide additional information and therefore did not change the surgical plan in the majority of these patients. In only $15 \%$ of patients did the Doppler studies result in change of the plan of treatment. Six of them were previously treated for varicose vein by general surgeons in other hospitals and 8 were obese with chronic venous insufficiency.

Therefore, we suggest that Doppler vascular laboratory studies should be reserved for this group of patients. Restricting vascular laboratory studies to these indications should reduce the workload of the laboratory, decrease demand on equipment, save money and permit allocation of resources to other areas.

Duplex scanning and hand-held Doppler are accurate for the identification of reflux sites (saphenofemoral and saphenopopliteal junctions) and recurrent disease [4-14]. Previous retrospective studies showed that traditional clinical examination alone was unreliable in assessing varicose veins and that Doppler and duplex are more reliable for the diagnosis of primary varicose veins $[8,11-16]$. However, surgery for primary varicose veins based upon the hand-held Doppler alone missed 24\% of reflux sites untreated [5].

Our findings are similar to two recent prospective studies in which Aiono et al. [17] reported higher sensitivity and specificity of clinical examination alone over the hand-held Doppler examination in the diagnosis of the short saphenous vein pathology, and Smith et al. [18], who studied 149 patients and showed that no additional benefit was gained from preoperative duplex scanning over that of clinical and hand-held Doppler. 


\section{Conclusion}

This prospective study demonstrated that a focused and detailed clinical examination is sufficient to diagnose most primary varicose vein patients. However, Doppler ultrasound examination was useful in changing the treatment modality in 6 patients with recurrent varicose vein and in 8 obese patients with chronic venous insufficiency.

\section{Acknowledgment}

The authors pay tribute to their late colleague Dr. Hisham Abdul-Ghafar and acknowledge his assistance in an early phase of this study.

\section{References}

1 Campbell WB: Varicose veins. BMJ 1990;300: 763-764.

2 Fegan WG: Continuous uninterrupted compression technique of injecting varicose veins. Proc R Soc Med 1960;53:837-840.

3 Maffei FH, Magaldi C, Pinho SZ, Lastoria S, Pinho W, Yoshida WB, Rollo HA: Varicose veins and chronic venous insufficiency in Brazil: Prevalence among 1,755 inhabitants of a country town. Int J Epidemiol 1986;15:210 217.

4 Bradbury AW, Stonebridge PA, Callam MJ, Walker AJ, Allen PL: Recurrent varicose veins: Assessment of the saphenofemoral junction. $\mathrm{Br}$ J Surg 1994;81:373-375.

5 Mercer KG, Scott DJA, Berridge DC, Weston $\mathrm{M}$ : Out-patient varicose vein assessment: Hand-held Doppler or duplex scanning? Br J Surg 1996;83:563-564.

6 Lees T, Singh S, Beard J, Spencer P, Rigby C: Prospective audit of surgery for varicose veins. Br J Surg 1997;84:44-46.

7 Vasdekis SN, Clarke GH, Hobbs JT, Nicolaides AN: Evaluation of non-invasive and invasive methods in the assessment of short saphenous vein termination. Br J Surg 1989;76: 929-932.
8 Salaman RA, Fligelstone LJ, Wright IA, Pugh N, Harding KG, Lane IF: Hand-held bi-directional Doppler versus colour duplex scanning in the pre-operative assessment of varicose veins. J Vasc Inv 1995; 1:183-186.

9 Darke SG, Vetrivel S, Foy DM, Smith S, Baler $\mathrm{S}$ : A comparison of duplex scanning and continuous wave Doppler assessment of primary and uncomplicated varicose veins. Eur J Vasc Endovasc Surg 1997;14:457-461.

10 Kim J, Richards S, Kent PJ: Clinical examination of varicose veins: A validation study. Ann R Coll Surg Engl 2000;82:171-175.

11 Pleass HCC, Holdsworth JD: Audit of introduction of hand-held Doppler and duplex ultrasound in the management of varicose veins. Ann R Coll Surg Engl 1996;78:494-496.

12 Mitchell DC, Darke SG: The assessment of primary varicose veins by Doppler ultrasound-the role of sapheno-popliteal incompetence and the short saphenous systems in calf varicosities. Eur J Vasc Surg 1987;1:113-115.
13 McIrvine AJ, Corbett CR, Aston NO, Sheriff EA, Wiseman PA, Jamieson CW: The demonstration of saphenofemoral incompetence: Doppler ultrasound compared with standard clinical tests. Br J Surg 1984;71:509-510.

14 Royle JP: Recurrent varicose veins. World J Surg 1986;10:944-953.

15 Hoare MC, Royle JP: Doppler ultrasound detection of saphenofemoral and saphenopopliteal incompetence and operative venography to ensure precise saphenopopliteal ligation. Aust N Z J Surg 1984;54:49-52.

16 Singh S, Lees TA, Donlon M, Harris N, Beard JD: Improving the preoperative assessment of varicose veins. Br J Surg 1997;84:801-802.

17 Aiono S, Simmons MJ, Galland RB, Magee TR: Is a palpable short saphenous vein a useful clinical sign in varicose vein assessment? Ann R Coll Surg Engl 2001;83:105-107.

18 Smith JJ, Brown L, Greenhalgh RM, Davies AH: Randomised Trial of Pre-operative Colour Duplex Marking in Primary Varicose Vein Surgery: Outcome is not improved. Eur J Vasc Endovasc Surg 2002;23:336-343. 